\title{
Perceptions, impact and management of asthma in South Africa: a patient questionnaire study
}

\author{
*Robin Greena, Gloria Davis ${ }^{b}$, David Price \\ a Professor, Department of Paediatrics and Child Health, University of Pretoria, South Africa \\ ${ }^{b}$ General Practitioner, Johannesburg, South Africa \\ c GPIAG Professor of Primary Care Respiratory Medicine, University of Aberdeen, Scotland, UK
}

Originally submitted 28th November 2007; resubmitted 14th January 2008; revised version received 18th February 2008; accepted 4th March 2008; online 14th April 2008

\begin{abstract}
Introduction: A number of studies from around the world have indicated that asthma morbidity is still unacceptably high. In the AIRE study over one-third of children and half of the adults reported daytime symptoms at least once a week. This study was conducted to understand the impact (including the impact on health-related quality of life) of asthma on South African asthmatics.

Materials and methods: General Practitioners (GPS) and pharmacists in South Africa-were randomly identified from the Medical Association database. These individuals were approached and asked to recruit asthmatic patients to complete a questionnaire. The questionnaire inquired about symptoms, quality of life, complications, triggen factors, associated allergic conditions, medication used, medication preference, medication adherence and concerns about the condition.

Results: 3347 respondents returned their demographic data but only 710 met the criteria for analysis, ie. had asthma and were presently on controller medication. Symptom analysis revealed that $21.4 \%$ of respondents were coughing on most days, $25.6 \%$ were wheezing on most days, and $22.8 \%$ were experiencing night-time symptoms on most days. Symptoms were exacerbated by exercise in $56.9 \%$, while nocturnal wakening due to asthma occurred in $36.9 \%$ more than four times per week. Only $35.1 \%$ of respondents had not missed school or work in the preceding year. $45.4 \%$ of individuals worry about side effects of asthma therapy.

Conclusion: This study indicates that there is under-treatment, inappropriate treatment and/or lack of patient education for asthma patients in South Africa. The data support the notion that poor therapy and/or poor patient adherence has an enormous impact on the health-related quality of life of South Africa's asthmatics.

(c) 2008 General Practice Airways Group. All rights reserved.

R Green, et al. Prim Care Resp J 2008; 17(4): 212-216.

doi:10.3132/pcrj.2008.00027
\end{abstract}

\section{Keywords Asthma}

See Appendix A at www.thepcri.org for Questionnaire for asthma sufferers

\section{Introduction}

Asthma is one of the commonest chronic diseases, affecting at least 1 in 10 people. It knows no prejudice, affecting people from all social, cultural and ethnic backgrounds unlike tuberculosis, which one would expect to encounter in less privileged societies, and coronary artery disease, which is a disease of affluence. Therefore, no matter where the healthcare giver (ie. doctor, nurse or pharmacist) practises he or she will see patients with asthma every day. This interaction with asthmatic patients is often limited - even in a medical setting - to the medical or clinical effects, and treatment, of the disease. These are very well known. Less well known, and certainly seldom discussed, are the quality of life, social, and psychological consequences of asthma as a chronic illness.

Some of these issues were highlighted in an important study from the UK in 1992; known as the Lifestyle Study, it

\footnotetext{
* Corresponding author: Professor Robin Green, Department of Paediatrics and Child Health, University of Pretoria, PO Box 667, Pretoria 0001, South Africa. Tel: +27123545272 Fax: +27123545275 E-mail: robin.green@up.ac.za
} 
was one of the first large studies to focus on quality of life, which has now become an important concept in the assessment of chronic illnesses. The Lifestyle Study revealed a significant impact of asthma (even so-called "treated" asthma) on the lives of individuals with the condition. Further asthma-related quality of life studies and assessments of asthma control followed. ${ }^{2-5}$ They reflect a dismal picture of asthma control around the world. ${ }^{6}$ Such social or psychological impact goes beyond the disease itself. Poor sleep will produce a tired child who is unable to concentrate in class; this, in addition to school absence, has a dramatic impact on the academic potential of children with asthma. ${ }^{7}$ Two further UK studies on asthma-related school absences showed that $60 \%$ of children had taken days off due to episodes of wheeze in the past year. ${ }^{8,9}$ In their study of 284 children, Anderson and colleagues ${ }^{8}$ reported that in the 30 $(12 \%)$ most severely affected children, each child lost, on average, 30 days schooling each year - giving a total of 900 days of schooling missed. The emotional impact of asthma on the child and family were likewise considerable, with fear and embarrassment common emotions when experiencing an attack. These and other emotional effects have a direct bearing on the family of the asthmatic, due to limited activity and tensions and the eventual impact on other aspects of quality of life.

In addition to these consequences of asthma, a number of studies from around the world have indicated that asthma morbidity is still unacceptably high. The Asthma linsights and Reality in Europe (AIRE) survey assessed the tevel of asthma control, among current asthmatics in Western Eyrope, from the patient's perspective. ${ }^{2}$ Over one-third of children and half of the adults reported daytime symptoms at least once a week. Furthermore, $28.0 \%$ of children and $30.5 \%$ of adults experienced asthma-related sleep disturbances at least once a week. Patient perception of asthma control did not match symptom severity, since approximately $50 \%$ of those reporting severe persistent symptoms considered their asthma to be completely or well controlled. In addition, it should be remembered that this social cost of asthma, or impact on health-related quality of life, will eventually have a direct monetary cost, adding to the cost of medication and consultations. Subsequent and recent studies have revealed that between $49 \%{ }^{10}$ and $53 \%{ }^{11}$ of asthmatics in Europe and Canada, respectively, have uncontrolled asthma.

The aim of this study, therefore, was to understand the impact (including the health-related quality of life impact) of asthma on South African asthmatics, following documentation of these parameters in South Africa's rural asthma patients. ${ }^{12}$ There is a need to understand the complexities of asthma control in this country and to determine the burden of asthma morbidity.

\section{Materials and methods}

Questionnaire (see Appendix A at ww w.thepcrj.org)

A questionnaire, appropriate to South Africa, was compiled and subjected to pilot testing amongst a group of patients attending the authors' allergy clinics and practices. A list of 100 possible questions was reduced to the current questionnaire after discussion between a group of 25 asthmatics, 10 doctors and 10 pharmacists. Questions were retained if more than $80 \%$ of subjects felt the question was relevant, understandable and meaningful. In addition, the question responses had to match objective assessment of asthma control and medication usage in the patients. The pilot study revealed that the language was understandable by all patients (including those with limited formal education and patients from different racial groups) and the question results correlated well with objective observer assessment of asthma control. The questionnaire (see Appendix $A$ at www.thepcrj.org) inquired about symptoms, quality of life, complications, trigger factors, associated allergic conditions, medication used, M̂edication preference, medication adherence and concerns about the condition. Respondents were asked about perceived concerns around having, and being treated for, asthma.

\section{Patient recruitment}

General) Practitioners (GPs) and pharmacists were randomly identified from the South African Medical Association database and were approached to recruit patients. The study was conducted between October 2002 and October 2004. Twenty of each group were identified in each of five major centres (Johannesburg, Pretoria, Durban, Cape Town and Bloemfontein). Each site was selected by a random number generator of practice numbers. The GPs and pharmacists invited patients, whom they believed had asthma, to complete the questionnaire. No attempt was made to define asthma or asthma severity in these patients. The questionnaire was entitled 'Questionnaire for asthma sufferers'. No attempt was made to select specific patients of disease type or severity. The survey was, how ever, targeted to patients and was not a random population sample. All respondents completed written informed consent, and ethics approval (from the Medicines Control Council South Africa) was obtained for the study. Despite a large number of responses to the survey, only asthmatic patients presently on controller medication were analysed.

\section{Results}

3347 patients ( 2340 female) ranging in age from 5 - 67 years (mean 32 years) completed the questionnaire and returned the survey. Parents of children were asked to complete the questionnaire on behalf of children unable to do so. The number of 'proxy' responses was less than 50. There was a 


\begin{tabular}{|c|c|c|c|c|c|c|c|c|c|c|c|c|}
\hline \multirow{2}{*}{$\begin{array}{l}\text { Symptom } \\
\text { Coughing }\end{array}$} & \multicolumn{2}{|c|}{ Every day } & \multicolumn{2}{|c|}{ Most days } & \multicolumn{2}{|c|}{$\begin{array}{c}\text { More than } \\
\text { once a week }\end{array}$} & \multicolumn{2}{|c|}{$\begin{array}{c}\text { More than } \\
\text { once a month }\end{array}$} & \multicolumn{2}{|c|}{ Never } & \multicolumn{2}{|c|}{ Not answered } \\
\hline & 135 & 19.0 & 152 & 21.4 & 121 & 17.0 & 160 & 22.5 & 60 & 8.5 & 82 & 11.6 \\
\hline Wheezing & 134 & 18.9 & 182 & 25.6 & 148 & 20.9 & 142 & 20.0 & 43 & 6.1 & 61 & 8.6 \\
\hline Night-time symptoms & 159 & 22.4 & 162 & 22.8 & 124 & 17.5 & 159 & 22.4 & 45 & 6.3 & 61 & 8.6 \\
\hline
\end{tabular}

\section{Table 2. Asthma attacks per month [n, \% ].}

\begin{tabular}{lrllllll} 
& \multicolumn{2}{c}{$0-2$} & \multicolumn{2}{c}{$2-4$} & & More than 4 \\
\hline At night & 218 & 30.7 & 136 & 19.2 & 262 & 36.9 \\
\hline $\begin{array}{l}\text { After exercise / } \\
\text { activity }\end{array}$ & 148 & 20.9 & 118 & 16.6 & 284 & 40.0
\end{tabular}

response rate of $83 \%$. Two thirds $(69 \%)$ of questionnaires were returned from GPs. There was no significant difference in response rate between these groups.

3347 respondents returned their demographic data but only 710 met the criteria for analysis, ie. had asthma and were presently on controller medication. There was a fairly uniform spread across the provinces of South Africa. There were no particular trends revealed by sex or age differences. Although the individual drugs used by these patients were noted, no relationship between type, dose or duration, and the measures of asthma control questioned was seen, Many patients were not able to recall their exactidrug dosage.

Symptom analysis revealed that most patients still had symptoms of asthma; $21.4 \%$ were coughing on most days, $25.6 \%$ were wheezing on most days, and $22.8 \%$ were experiencing night-time symptoms on most days (see Table 1 ). Symptoms were exacerbated by exercise in $56.9 \%$ and by sport in $60.6 \%$, probably reflecting similar patient groups.
Daily activities caused symptom exacerbation in $46.2 \%$ (with $6.5 \%$ not answering this question). Nocturnal wakening due to asthma occurred frequently with $22.4 \%$ of respondents having nocturnal symptoms every day and $31.9 \%$ of respondents being woken more than four times per month due to asthma attacks (see Table 2).

Trigger factors for exacerbations and "attacks" are listed by the frequency with which they produced symptoms, in Table 3. $23.8 \%$ of respondents believed that air pollution caused symptoms every day, $28.3 \%$ on most days, and $4.4 \%$ seldom/never. Foobas a trigger factor was generally reported as being uncommon, with respondents claiming a relationship (at most) more than once a month but less than oncea week in $17.5 \%$; this was the least common trigger factor reported, with a prevalence in the range of that for "emotional upset".

The vast majority of patients had associated "allergic" diseases - hay fever in $81.4 \%$, blocked nose in $62.3 \%$ and eczema in $44.9 \%, 16.9 \%$ of responders did not answer the question on eczema, possibly because they didn't understand the condition.

With regard to quality of life, certain pertinent responses were received. Table 4 demonstrates the number of patients missing school or work due to disease, and the length of time off. Only $35.1 \%$ of respondents had not missed school or work in the preceding year; $26.3 \%$ had missed $1-3$ days while

\section{Table 3. Frequency with which common exposures result in symptom exacerbations [n, \% ].}

\begin{tabular}{|c|c|c|c|c|c|c|c|c|c|c|}
\hline \multirow{2}{*}{$\begin{array}{l}\text { Symptom } \\
\text { Smoky atmosphere }\end{array}$} & \multicolumn{2}{|c|}{ Every day } & \multicolumn{2}{|c|}{ Most days } & \multicolumn{2}{|c|}{$\begin{array}{c}\text { More than } \\
\text { once a week }\end{array}$} & \multicolumn{2}{|c|}{$\begin{array}{c}\text { More than } \\
\text { once a month }\end{array}$} & \multicolumn{2}{|c|}{ Never } \\
\hline & 205 & 28.9 & 184 & 25.9 & 134 & 18.9 & 73 & 10.3 & 41 & 5.8 \\
\hline Air pollution & 169 & 23.8 & 201 & 28.3 & 161 & 22.7 & 58 & 8.2 & 31 & 4.4 \\
\hline Weather & 204 & 28.7 & 219 & 30.9 & 132 & 18.6 & 67 & 9.4 & 64 & 9.0 \\
\hline Pollen & 116 & 16.3 & 148 & 20.9 & 118 & 16.6 & 100 & 14.1 & 81 & 11.4 \\
\hline Food & 45 & 6.3 & 53 & $7.5 \%$ & 121 & 17.0 & 124 & 17.5 & 203 & 28.6 \\
\hline Emotional upset & 146 & 20.6 & 130 & 18.3 & 124 & 17.5 & 118 & 16.6 & 94 & 13.2 \\
\hline
\end{tabular}




\begin{tabular}{|c|c|c|}
\hline No time & 128 & 35.1 \\
\hline 1 - 3 days off & 96 & 26.3 \\
\hline 4 - 7 days off & 64 & 4.5 \\
\hline 1 - 2 weeks off & 39 & 10.7 \\
\hline $2-4$ weeks off & 28 & 7.7 \\
\hline More than 5 weeks & 3 & 0.8 \\
\hline Not worked - asthma & 7 & 1.9 \\
\hline
\end{tabular}

$10.7 \%$ had missed 1 -2 weeks. $15.9 \%$ of responders had been admitted to hospital in the previous year. Patients reported a doctor call-out, visit to the doctor, or visit to casualty, in $13.9 \%, 27.3 \%$ and $24.8 \%$ of cases, respectively.

With regard to the use of prescribed inhaled medication, a number of general questions were asked. Patient-listed reasons for non-adherence and concern about taking medication for asthma are shown in Table 5. 45.4\% of individuals were worried about the side effects of asthma therapy and $321(45.2 \%)$ of respondents admitted to stopping controller medication when feeling better.

Finally, the group was asked about home use of peak flow meters; $35.9 \%$ used one at home, and another $14.4 \%$ used their meter together with a diary card.

\section{Discussion}

This study has a number of significant limitations. Firstly, the questionnaire has not been validated noor transtated into multiple languages. The complexity of some of the questions - such as that directed at symptom causation, with a matrix of symptom frequency and patient-perceived causation of symptoms (see Appendix A at www.thepcrj.org) - may have posed problems for patients in terms of their understanding and responding. For this question specifically, 73 patients $(10.3 \%)$ did not answer the question on whether or not a smokey atmosphere caused symptoms. Secondly, the questionnaire is not specifically one relating to a quality of life study but is an attempt to document asthma control in South Africans. Employing other validated, international quality of life questionnaires, would be a useful follow-up tool. Thirdly, some questions were deliberately not defined in order to assess what patients understand, perceive, and do, independent of the medical label. One such example is the definition of an 'asthma attack'. Not all respondents answered every question and some results reflect missing data points - hence not all totals add up to $100 \%$. Clearly the label of 'asthma' should be investigated and defined; however, this study reflects the real-world experience of patients who are labelled 'asthmatic' and then left to
Table 5. Patient-listed reasons for non-adherence and concern about taking medication for asthma $[n, \%]$.

\begin{tabular}{|c|c|c|}
\hline & $\mathrm{n}$ & $\%$ \\
\hline I sometimes forget to take my medicine & 202 & 28.5 \\
\hline I sometimes forget how many doses I have taken & 98 & 13.8 \\
\hline I worry about side effects of the medicine & 322 & 45.4 \\
\hline I have difficulty using my inhaler & 46 & 6.5 \\
\hline $\begin{array}{l}\text { I am not sure I am getting the right amount } \\
\text { of medicine }\end{array}$ & 132 & 18.6 \\
\hline I don't know how to take my medicine properly & 28 & 3.9 \\
\hline I do not like the method of taking my medicine & 59 & 8.3 \\
\hline I take what I think I know I need & 300 & 42.3 \\
\hline I feel that taking medicine is admitting defeat & 73 & 10.3 \\
\hline $\begin{array}{l}\text { I am embarrassed to take my medicine in front of } \\
\text { other people }\end{array}$ & 199 & 28.0 \\
\hline I cannot afford to pay for my medicine & 203 & 28.6 \\
\hline $\begin{array}{l}\text { I sometimes stop taking my medicine when I } \\
\text { feel better }\end{array}$ & 321 & 45.2 \\
\hline $\begin{array}{l}\text { I prefer not to take my my medicine unless I feel } \\
\text { it is absolutely necessary }\end{array}$ & 282 & 39.7 \\
\hline $\begin{array}{l}\text { I worry that feell } \text { might be taking too much } \\
\text { medicine }\end{array}$ & 181 & 25.5 \\
\hline I am saving my medicine for bad attacks & 122 & 17.2 \\
\hline
\end{tabular}

experience ongoing morbidity, without either review of the diagnosis or attempts at education. Finally, this study is part of an ongoing survey of health needs of South Africans with allergic diseases; these conditions often take a back seat to more serious infectious diseases.

This study does not stratify respondents by socioeconomic status and the responses may mask trends in certain populations. However, the source of data from the questionnaires was standardised - i.e. the pharmacies and doctors - and therefore it is unlikely that large "unusual" groups would skew the findings. The number of individuals who were labelled as asthmatic by their doctor who thought they had asthma but were not using anti-inflammatory therapy raises a concern. Clearly asthma diagnosis may not always be correct (and this fact was not tested nor investigated) and some of these patients may have mild persistent asthma by definition. However, the large number and significant level of ongoing symptoms in those receiving controller therapy suggests that possible under-management of asthma is a major problem.

The decision not to report drug type and dosage and to compare it to symptom control is based on two reasons; firstly, many patients could not recall their drug dosage, and secondly the drug and dosage prescribed or taken is clearly inadequate. 
The primary finding of this study is the number of patients with active symptoms despite diagnosis and therapy - $21.4 \%$ coughing on most days, $25.6 \%$ wheezing on most days, and $22.8 \%$ experiencing night-time symptoms on most days. For this reason, and also given the excessively high number of patients who have symptoms triggered by either exercise or daily activity, there is a clear case to be made for there being under-treatment, inappropriate treatment, and/or lack of patient education in the asthmatic population studied. Most asthma guidelines state that a normal and physically active life is a goal of asthma management. ${ }^{13-15}$

A significant number of patients are missing school or work due to asthma. The response rate of $51 \%$ for this question reflects a large number of women who are not formally employed. As a gross estimate of quality of life, the rate of hospital admission and crisis control visits were recorded; there was an unacceptably high rate of asthma exacerbations requiring emergency care (though it is encouraging to note that peak flow usage is being introduced.) The rate of symptom exacerbation, as well as the rate of acute attacks, crisis consultations with the doctor, and/or hospitalisation rates, not only supports the notion of poor therapy - or possibly poor adherence - but also suggests an enormous impact on the health-related quality of life of South Africa's asthmatics. This cannot be solely due to poor adherence; it strongly suggests a failure on behalf of the medical fraternity to educate patients completely.

There are some interesting reflections on the well-known asthma triggers. Common factors included triggers such as smokey atmosphere, weather change, pets and environmental pollution. Food was hot identified as a major trigger factor, thereby supporting a common belief.

When comparing this survey to other studies, particularly the study of asthma control in rural South Africa, ${ }^{12}$ similar findings are seen. In that group of 35 asthmatics, 19 (31\%) had wheeze at least once a week, $26(42 \%)$ cough at least once a week and $33(53 \%)$ were being woken by symptoms at least once a week. This latter figure of $53 \%$ is similar to the figure in this study of $62.7 \%$. The number of South African asthmatics in this study who do report complete asthma control is remarkably similar to the average of $6 \%$ quoted for world surveys. ${ }^{2-6}$ The Lifestyle study ${ }^{1}$ noted that $60 \%$ of children had taken days off school due to episodes of wheeze in the past year. Our study demonstrates a similar figure $(64.9 \%)$ for both children and adults absent from daily activities due to asthma. As in the study by Anderson and colleagues, ${ }^{8}$ days lost translate into significant costs to educational needs and to the economy.

\section{Conclusion}

The limitations of this study aside, it seems obvious that the need for asthma control has been under-recognised and poorly attended to in South Africa. The National Asthma Education Programme of South Africa now has a clear mandate to upgrade education of both doctors and patients. Luckily there are moves afoot in this arena and the mere publication of asthma guidelines is now recognised as being insufficient to address this problem.

\section{Conflict of interest declaration}

No conflict of interest to declare.

\section{References}

1. Lenney W, Wells NEJ, O'Neill BA. The burden of paediatric asthma. Eur Resp J 1994;4:49-62.

2. Rabe KF, Vermiere PA, Soriono JB, Maier WX. Clinical Management of Asthma in 1999: The Asthma Insights and Reality in Europe (AIRE) study. Eur Respir J 2001;16(5):802-07.

3. Lai CK, De Guia TS, Kim YY, et al. Asthma control in the Asia-Pacific region: the Asthma insights and Reality in Asia-Pacific Study. J Allergy Clin Immunol 2003;111:263-8.

4. Adachi M, Morikawa A, Ishihara K. Asthma insights and reality in Japan. Arerugi 2002;51:411-20.

5. Asthma in America. http://www.asthmainamerica.com 2002 (accessed 12 December 2007)

Rabe KF, Mitsuru A, Christopher K, et al. Worldwide severity and control of asthma in children and adults: the global asthma insights and reality surveys. J Allergy Clin Immunol 2004;114:40-7.

7. O'Neill SL, Barysh N, Setear SJ. Determining school-programming needs of special population groups: a study of asthmatic children. J Sch Health 1985; 55:237-9.

8. Anderson HR, Bailey PA, Cooper JS, et al. Morbidity and school absence caused by asthma and wheezing illness. Arch Dis Child 1983;58:777-84.

9. Hill RA, Standen PJ, Tattersfield AE. Asthma, wheezing and school absence in primary schools. Arch Dis Child 1989;64:246-51.

10. Cazzoletti L, Marcon A, Janson C, et al. Asthma control in Europe: A real-world evaluation based on an international population-based study. J Allergy Clin Immunol 2007;120:1360-7.

11. Mclvor RA, Boulet LP, FitzGerald JM, Zimmerman S, Chapman KR. Asthma control in Canada: no improvement since we last looked in 1999. Can Fam Physician 2007;53:673-7.

12. Green RJ, Greenblatt M M, Plit M, Jones S, Adam B. Asthma Management and perceptions in rural South Africa. Annals Allergy Asthma Immunol 2001;86: 343-7.

13. South African Childhood Asthma Working Group. Management of childhood and adolescent asthma. S Afr Med J 1994;84:862-6.

14. National Heart Lung and Blood Institute. National Asthma Education Programme. Guidelines for the diagnosis and management of asthma. Expert Panel Report. J Allergy Clin Immunol 1991;88 suppl.(part 2).

15. Global Initiative for Asthma (GINA). Global strategy for asthma management and prevention. Workshop Report. 2006; MCR Vision (publ). www.ginasthma.com (accessed 18 February 2008)

Available online at http://w w w.thepcrj.org 
Appendix 1. The Asthma CARE Programme

Date of Birth

Day Month Year

Patient Identifying Number

Please complete this questionnaire and return it by the date indicated in the newsletter to:

The Asthma CARE Programme, Private Bag X6, Fairland.

The answers you give will be kept fully confidential. This will help us to send you relevant information specifically designed to help your condition as you describe it. Thank you.

\section{QUESTIONNAIRE FOR ASTHMA SUFFERERS}

1. Which of the following asthma symptoms do you experience, and how often?

\begin{tabular}{|l|l|l|l|l|}
\hline Symptom & Everyday & Most days & More than once a week & Never \\
\hline Coughing & & & & \\
\hline Wheezing (noisy breathing) & & & & \\
\hline $\begin{array}{l}\text { Night-time symptoms (experiencing } \\
\text { coughing, wheezing or tightness } \\
\text { of chest in bed) }\end{array}$ & & & \\
\hline
\end{tabular}

2. When and how often do you experience asthma attacks per month?

\begin{tabular}{|l|c|c|c|}
\hline When & $0-2$ times & More than 4 times \\
\hline At night & \\
\hline After exercise / activity & a & \\
\hline
\end{tabular}

3. Have asthma symptoms prevented you from doing activities such as:
a. Exercise
b. Sports
c. Daily activities (e.g climbing stairs]

$\begin{array}{ll}\text { Yes [ ] } & \text { No [ ] } \\ \text { Yes [ ] } & \text { No [ ] } \\ \text { Yes [ ] } & \text { No [ ] } \\ \text { Yes [ ] } & \text { No [ ] }\end{array}$
4. Do you feel self-conscious about your asthma?

5. How often has your asthma prevented you from working or caused you to take time off school (Total in the past 12 months)

\begin{tabular}{|l|l|}
\hline Lost no time off work / school & \\
\hline Lost $1-3$ days off work / school & \\
\hline Lost $4-7$ days off work / school & \\
\hline Lost $1-2$ weeks off work / school & \\
\hline Lost $2-4$ weeks off work / school & \\
\hline Lost more than 5 weeks off work / school & \\
\hline I have not worked because of asthma & \\
\hline
\end{tabular}

6. How many times in the past year have you

Been admitted to hospital with a bad attack of asthma Called a GP to your home because of back attack of asthma Attended your GP in his/her rooms because of your asthma Attended a hospital out-patient clinic because of your asthma 
Appendix 1. The Asthma CARE Programme continued

7. To what extent would you say your asthma is affected by each of the following factors? (PLEASE TICK ONLY ONE BLOCK FOR EACH FACTOR)

\begin{tabular}{|l|l|l|l|l|l|}
\hline Factor & Not at all & Very little & Moderately & Quite a lot & A great deal \\
\hline Smoky atmosphere (e.g. in a pub) & & & & & \\
\hline Being in an area affected by air pollution & & & & & \\
\hline Changes in weather (e.g. cold air) & & & & & \\
\hline Pets & & & & & \\
\hline Pollen & & & & & \\
\hline Food & & & & & \\
\hline Emotional upset & & & & & \\
\hline OTHER: Please specify & & & & & \\
\hline
\end{tabular}

8. Do you suffer from any of the following?
a. Hayfever (symptoms include itchy eyes, runny nose, sneezing)
b. Regular blocked nose
c. Eczema (symptoms include itchy skin and rash)

$\begin{array}{ll}\text { Yes [ ] } & \text { No [ ] } \\ \text { Yes[lO } & \text { No[ ] } \\ \text { Yest ] } & \text { No[ ] }\end{array}$

9. Which medicines are you currently taking for asthma?

\begin{tabular}{|c|c|c|c|}
\hline $\begin{array}{l}\text { Name of medicine } \\
\text { (brand name on pack) }\end{array}$ & $\begin{array}{l}\text { Strength of medicine } \\
\text { (shown on pack, } \\
\text { e.g. } 20 \mathrm{mcg}, 100 \mathrm{mcg}\end{array}$ & $\begin{array}{c}\text { Number of puffs/tablets } \\
\text { per day } \\
\text { (e.g. } 2,3)\end{array}$ & $\begin{array}{c}\text { For how long have you } \\
\text { been using it? } \\
\text { (e.g. } 6 \text { months, } 1 \text { year) }\end{array}$ \\
\hline \multicolumn{4}{|l|}{ Airomir } \\
\hline \multicolumn{4}{|l|}{ Atrovent } \\
\hline \multicolumn{4}{|l|}{ Becloforte } \\
\hline \multicolumn{4}{|l|}{ Becotide } \\
\hline \multicolumn{4}{|l|}{ Becotide } \\
\hline \multicolumn{4}{|l|}{ Clenil } \\
\hline \multicolumn{4}{|l|}{ Duovent } \\
\hline \multicolumn{4}{|l|}{ Flixotide } \\
\hline \multicolumn{4}{|l|}{ Floradil } \\
\hline \multicolumn{4}{|l|}{ Inflammide } \\
\hline \multicolumn{4}{|l|}{ Lomudal } \\
\hline \multicolumn{4}{|l|}{ Pulmicort } \\
\hline \multicolumn{4}{|l|}{ Salbulin } \\
\hline \multicolumn{4}{|l|}{ Seretide } \\
\hline \multicolumn{4}{|l|}{ Symbicord } \\
\hline \multicolumn{4}{|l|}{ Theo-Dur } \\
\hline \multicolumn{4}{|l|}{ Uni-Dur } \\
\hline \multicolumn{4}{|l|}{ Uniphyl } \\
\hline \multicolumn{4}{|l|}{ Venteze } \\
\hline \multicolumn{4}{|l|}{ Ventolin } \\
\hline \multicolumn{4}{|l|}{ Zaditen } \\
\hline OTHER: Please specify & & & \\
\hline
\end{tabular}


Appendix 1. The Asthma CARE Programme continued

10. Do you always follow the exact instructions for taking asthma medication? Yes [ ] No [ ]

11. Please tick whichever of the following statements you agree with:

\begin{tabular}{|l|l|}
\hline I sometimes forget to take my medicine & \\
\hline I sometimes forget how many doses I have taken & \\
\hline I worry about side effects of the medicine & \\
\hline I have difficulty using my inhaler & \\
\hline I am not sure that I am getting the right amount of medicine & \\
\hline I do not know how to take my medicine properly & \\
\hline I do not like the method of taking my medicine & \\
\hline I feel that taking medicine is admitting defeat & \\
\hline I am embarrassed to take my medicine in front of other people & \\
\hline I cannot afford to pay for my medicine & \\
\hline I sometimes stop taking my medicine when I feel better & \\
\hline I prefer not to take my medicine unless I feel it is absolutely necessary & \\
\hline I worry that I might be taking too much medicine & \\
\hline I am saving my medicine for bad attacks & \\
\hline
\end{tabular}

12. Who administers your medicine?

\begin{tabular}{|l|l|}
\hline Yourself \\
\hline Your father / mother \\
\hline Other relatives & \\
\hline Your teacher & \\
\hline Other & \\
\hline
\end{tabular}

13. What concerns do you have about asthma?

\begin{tabular}{|l|l|l|}
\hline & Yes & No \\
\hline That it may last life-long & & \\
\hline That you may not outgrow your asthma & & \\
\hline The choice of devices & & \\
\hline The effects of the medicines & & \\
\hline Passing asthma on to your children & & \\
\hline
\end{tabular}

\section{Have you ever used .........}
a. A peak flow meter
b. A peak flow diary card

Yes [ ] No [ ]
Yes [ ] No [ ]

Thank you for completing this questionnaire 